\title{
An observational study of once-daily modified-release methylphenidate in ADHD: effectiveness on symptoms and impairment, and safety
}

\author{
Manfred Döpfner • Anja Görtz-Dorten • \\ Dieter Breuer • Aribert Rothenberger
}

Published online: 8 September 2011

(C) The Author(s) 2011. This article is published with open access at Springerlink.com

\begin{abstract}
ADHD affects over 5\% of children worldwide. It is typically treated with stimulant medications, and methylphenidate (MPH) is the most commonly prescribed. This study investigated the effectiveness, on symptoms and impairment, and safety of Equasym $\mathrm{XL}^{\circledR}$, a combination of $30 \%$ immediate-release and $70 \%$ modified-release $\mathrm{MPH}$, in the treatment of ADHD in daily clinical practice. This openlabel, observational, post-marketing surveillance study was conducted in 169 centres in Germany. Eligible patients, aged 6-17 years, were diagnosed with ADHD and about to begin treatment with Equasym $\mathrm{XL}^{\circledR}$. Effectiveness was assessed by physicians using the clinical global impression (CGI) severity and improvement scales; teachers and parents completed questionnaires evaluating ADHD symptoms and behavioural problems (DAYAS, FBB-ADHD and SDQ-P). Assessments were carried out at baseline, after 1-3 and 6-12 weeks of treatment. Of 852 enrolled patients, 822 were evaluable; $25.30 \%$ were treatment naïve, $69.84 \%$ had previously received different MPH formulations, and 4.87\% had received other medications. ADHD symptoms improved
\end{abstract}

Manfred Döpfner and Anja Görtz-Dorten contributed equally to this paper.

M. Döpfner · A. Görtz-Dorten · D. Breuer Department of Child and Adolescent Psychiatry, University of Cologne, Cologne, Germany

M. Döpfner $(\bowtie)$

Department of Psychiatry and Psychotherapy of Childhood and Adolescence, University of Cologne,

Robert-Koch-Str. 10, 50931 Koeln, Germany

e-mail: manfred.doepfner@uk-koeln.de

A. Rothenberger

Department of Child and Adolescent Psychiatry,

University of Göttingen, Göttingen, Germany from baseline to last visit for the majority of patients for all outcome measures. According to physician ratings of core ADHD symptoms, $75.73 \%$ of patients showed improvements on the CGI-Improvement scale, $17.77 \%$ had no change, and $6.50 \%$ worsened. In teacher and parent ratings, the effectiveness of Equasym $\mathrm{XL}^{\circledR}$ was rated better than prior therapy at all measured time points across the day, particularly late morning (teachers) and early afternoon (parents). Equasym XL ${ }^{\circledR}$ was generally well tolerated; only $3.16 \%$ of patients permanently discontinued treatment due to adverse events. Equasym $\mathrm{XL}^{\circledR}$ is effective and well tolerated in daily clinical practice.

Keywords ADHD - Methylphenidate $\cdot$ Modified-release . Post-marketing surveillance study · Observational study

\section{Introduction}

Attention deficit hyperactivity disorder (ADHD) is the most commonly diagnosed neurobehavioural disorder in childhood, affecting over 5\% of children worldwide [33]. Although there are differences between United States and European diagnostic criteria [6], according to both the Diagnostic and Statistical Manual of the American Psychiatric Association (DSM-IV-TR) and the International Classification of Diseases (tenth edition, ICD-10), ADHD (or hyperkinetic disorder [HKD] according to ICD-10) is characterised by inappropriate levels of inattention, hyperactivity and impulsivity, which constitute the so-called ADHD core symptoms. These are often accompanied by comorbid symptoms, such as aggressive behaviour, depressive mood, anxiety and tics, by learning difficulties [11], and by impairment of social functioning [15, 29]. ADHD symptoms are known to decline with age, and approximately half of 
those who had ADHD in childhood no longer meet the full diagnostic criteria for the disorder when they reach adulthood; however, up to $50 \%$ of childhood ADHD cases show continued clinically significant symptoms during adolescence and adult life, which can cause serious impairments in everyday life and increase the risk for drug dependence, depression and anxiety disorder [1, 17].

For decades, ADHD has been treated with stimulant medications, which in most cases produce a rapid and dramatic improvement in ADHD symptoms and in the behaviour of affected children [6]. The use of stimulants for the management of ADHD has caused increasing public concern that it might predispose children to substance abuse as adolescents or adults. However, several studies have been conducted to address this issue, and there is no consistent evidence that stimulant treatment in childhood or during high school leads to a higher risk of drug use and addiction [5]. Methylphenidate (MPH) is the most commonly prescribed stimulant for children with ADHD. It is believed to inhibit the reuptake of dopamine and noradrenaline into the presynaptic neuron, increasing their concentration in the extra-neuronal space and therefore enhancing neurotransmission [3]. MPH is mainly metabolised by de-esterification into ritalinic acid, which is pharmacologically inactive; this results in a short half-life of 2.0-3.0 $\mathrm{h}$ and a short duration of action. The maximum plasma concentration $\left(C_{\max }\right)$ of $\mathrm{MPH}$, and consequently its maximum effect, is reached $1.5-2.0 \mathrm{~h}$ after dosing [31].

Conventional, immediate-release (IR) MPH formulations have been used since the 1960s for the treatment of ADHD. Due to the short duration of action, MPH-IR needs to be administered repeatedly during the day to maintain effectiveness, 2-3 daily doses being required for most children [29]. Multiple dosing can be problematic, as it can cause adherence issues and complications related to privacy, stigmatisation by classmates, potential abuse and accountability of the school administration [25]. To overcome these problems, new long-acting formulations of MPH have been developed recently that combine IR and modified-release (MR) components [20, 32]. These MPH-MR formulations provide a rapid onset of therapeutic effect, while having a sufficient duration to eliminate the need for additional doses; furthermore, they have a biphasic plasma concentration profile that avoids acute tolerance.

Equasym XL ${ }^{\circledR 1}$ (Shire Pharmaceuticals Ireland Limited, Ireland) is a combination of MPH-IR and MR that uses a

\footnotetext{
${ }^{1}$ Equasym XL is the UK trade name, and is registered and marketed by Shire in the following countries under the following trademarks: Denmark, Equasym Depot; Finland, Equasym Retard; France, Quasym LP; Germany, Equasym Retard; Ireland, Equasym XL; Netherlands, Equasym XL; Norway, Equasym Depot; Sweden, Equasym Depot; South Korea, Metadate CD; Mexico, Metadate CD. Information correct at August 2011.
}

multi-particulate bead delivery system (Diffucaps ${ }^{\circledR}$ technology, Eurand Pharmaceuticals, USA); each Equasym $\mathrm{XL}^{\circledR}$ capsule contains $30 \%$ MPH-IR-coated beads and $70 \%$ MPH-MR-coated beads. Equasym XL ${ }^{\circledR}$ produces an initial fast increase in MPH plasma concentration followed by a second increase after approximately $3 \mathrm{~h}$, and therapeutic plasma concentration is maintained for about $8 \mathrm{~h}[40,44]$. Equasym $\mathrm{XL}^{\circledR}$ has a good safety profile and is effective in controlling ADHD symptoms in children aged 6 years and older throughout a period consistent with the school day and homework time, depending on the length of the school day [23]; it has been proven as effective as MPH-IR given twice daily [19].

Open-label studies can provide valuable data on therapeutic effects by reflecting the real-life setting better than controlled clinical trials [39]. Although clinical effectiveness of Equasym XL ${ }^{\circledR}$ has also been shown in an open-label study [12], no observational study has yet investigated the effectiveness of this MPH formulation using a structured combination of physician, teacher and parent ratings, as has been done for another MPH-MR formulation, Concerta ${ }^{\circledR}$ (Janssen-Cilag, High Wycombe, UK), in both European [24, 35] and Korean [26] populations. The OBSEER (OBservation of Safety and Effectiveness of Equasym XL ${ }^{\circledR}$ in Routine care) study was a non-controlled, non-interventional, postmarketing surveillance study conducted in Germany, designed to gain new insights into the effectiveness and safety of treatment with Equasym $\mathrm{XL}^{\circledR}$ under routine care conditions. The study included children diagnosed with ADHD or HKD — either previously untreated or treated with different MPH formulations, other drugs or non-pharmaceutical therapies-for whom therapy with Equasym $\mathrm{XL}^{\circledR}$ was already planned by the attending physician. The observation period for each patient was 6-12 weeks after the first use of Equasym $\mathrm{XL}^{\circledR}$, and effectiveness and safety were assessed by physicians, parents and teachers.

\section{Methods}

\section{Participants}

The study included male and female patients aged 6-17 years with a confirmed diagnosis of ADHD according to DSM-IV-TR (diagnostic codes 314.00 or 314.01) [2] or HKD according to ICD-10 (diagnostic codes F90.0, F90.1 or F90.8) [46], for whom therapy with Equasym XL ${ }^{\circledR}(10 /$ $20 / 30 \mathrm{mg}$ once daily) was already intended by the attending physician. Medication with long-acting MPH had to be indicated, and patients had to be attending school. Exclusion criteria included contraindications according to the summary of product characteristics and the presence of a mental handicap. 
Study design

This was a non-interventional, non-controlled, multicentre, prospective, observational, post-marketing surveillance study conducted in 169 centres in Germany in accordance with local regulations and under the therapeutic responsibility of the attending physicians; ethics or institutional review board approval was not required for this study. Written informed consent was obtained from parents.

Physicians (specialists in paediatrics and/or child and adolescent psychiatry) were asked to select appropriate patients for whom therapy with Equasym $\mathrm{XL}^{\circledR}$ was indicated. The required examinations were recorded at baseline (Visit 1), at a follow-up visit 1-3 weeks after the first use of Equasym XL ${ }^{\circledR}$ (Visit 2) and at a final visit 6-12 weeks after the first use of Equasym $\mathrm{XL}^{\circledR}$ (Visit 3). The information collected at Visit 1 included general data for the patient (sex, age, height, body weight, type of school and class), oral history of ADHD (duration, diagnosis in therapy-naïve patients according to the diagnostic checklist for HKD [DCL-ADHD] [14], timing of severe ADHD symptoms, current ADHD treatment including dose and administration mode), previous pharmaceutical and nonpharmaceutical treatment of ADHD, concomitant diseases and medications, rationale for Equasym $\mathrm{XL}^{\circledR}$ treatment in therapy-naïve patients and for switching therapy in previously treated patients, and details of the planned treatment with Equasym $\mathrm{XL}^{\circledR}$. The study started on 2 November 2006; inclusion of patients concluded on 28 February 2007, and observation was completed on 27 December 2007.

\section{Outcome measures}

Effectiveness was assessed by physicians using the clinical global impression severity (CGI-S) and Improvement (CGI-I) scales to rate ADHD core symptoms (inattention, hyperactivity and impulsivity) and disease-associated problems (aggressive behaviour, depressive mood, anxiety, tics and learning difficulties). CGI-S and CGI-I scores were recorded at each study visit. Categories for evaluation of CGI-S were as follows: $0=$ normal; $1=$ mild; $2=$ moderate; $3=$ severe. Categories for CGI-I during treatment, compared with the conditions before treatment with Equasym $\mathrm{XL}^{\circledR}$, were as follows: $-3=$ very strongly worsened; $-2=$ strongly worsened; $-1=$ slightly worsened; $0=$ unchanged, $+1=$ slightly improved $;+2=$ strongly improved; $+3=$ very strongly improved.

Teachers and parents completed the German ADHD Symptom Checklist (Fremdbeurteilungsbogen für Aufmerksamkeitsdefizit-Hyperaktivitätsstörung, FBB-ADHD) $[9,16]$ for each visit. FBB-ADHD is part of the German Diagnostic System for Mental Disorders in Children and Adolescents (DISYPS-II) [13] and assesses the diagnostic criteria for ADHD according to DSM-IV-TR and for HKD according to ICD-10. The presence of 20 symptom items is rated on a scale ranging from $0=$ not at all to $3=$ very much, with higher scores indicating more severe symptoms. Nine symptom items are combined into a subscale assessing inattention, and 11 items are combined to assess hyperactivity and impulsivity; the total symptom score (ADHD total) covers all 20 symptom items. In addition, four items evaluate functional impairment with respect to school performance, relationship towards adults and children, and the subjective level of suffering (functional impairment subscale), and six items assess competences regarding attentive, reflexive and enduring behaviour (attention-reflexivity subscale). Scale scores represent the sum of the individual item scores divided by the number of items in each respective scale. The reliability and validity of the scale scores in parent and teacher ratings have been established in several studies $[8,13,16]$.

Teachers and parents also assessed ADHD symptoms and other externalising problems for each visit using the Day Profile of ADHD Symptoms (DAYAS) [7]. The day profile of ADHD assessment is a new rating scale that assesses the daily profile of ADHD externalising symptoms from early morning until bedtime. The rating scale evaluates six items: (1) hyperactivity, (2) inattention, (3) impulsivity, (4) oppositional behaviour, (5) aggressive behaviour and temper tantrums and (6) a global rating of problem behaviour. The teacher version of the questionnaire (DAYAS-T) considers the first and second part of the morning at school (in Germany, children usually visit school only in the morning), while the parent version (DAYAS-P) considers four daily periods: early morning (before school), early afternoon until $4.00 \mathrm{pm}$, late afternoon until $7.00 \mathrm{pm}$ and evening. Parents and teachers rate the items in each period on a four-point scale using the following values: $0=$ not at all; $1=$ just a little; $2=$ pretty much; $3=$ very much. The total score ('overall assessment') is the sum of the six item scores per time period divided by the number of items; in addition, the first three items are combined into the subscale 'ADHD symptoms', and items 4 and 5 are combined into the subscale 'oppositional defiant disorder symptoms (ODD)'. Ratings were conducted during the week preceding each assessment point (Visit 1, Visit 2 and Visit 3) and cover the typical behaviour of the child at different times of the day during that week. The reliability and validity of both the parent and the teacher versions of DAYAS have been established in several studies [7].

Parents were also asked to complete the Strengths and Difficulties Questionnaire (SDQ-P) at baseline. SDQ is a brief behavioural screening questionnaire [21], covering five scales: emotional symptoms, hyperactivity, conduct problems, peer relationship problems and pro-social 
behaviour. Scores were calculated for each subscale and were combined into an overall difficulties score as the sum of the four problem scales (i.e. excluding pro-social behaviour). Each scale was classified as normal, borderline or abnormal according to the thresholds established by Woerner et al. [45] and Rothenberger et al. [38] based on German population norms.

\section{Adverse events}

Adverse events (AEs) were evaluated by the treating physician at each study visit, coded according to the Medical Dictionary for Regulatory Activities (MedDRA) version 11.1 and classified into AEs and serious AEs. Physicians were also asked to record whether the $\mathrm{AE}$ occurred during previous treatment or while receiving Equasym $\mathrm{XL}^{\circledR}$. Criteria of seriousness included occurrences leading to death, life-threatening conditions, hospitalisation or prolongation of hospitalisation, persistent injury/disability, incapacity for work, medically significant conditions and congenital abnormalities/birth defects.

\section{Statistical analysis}

The study planned to recruit a representative sample of 1,000 patients from 200 physicians, aiming for five patients per participating physician. This sample size was calculated to allow detection of any rare adverse drug reactions, with a power of $86 \%$ for an event with a probability of 0.2 , and $63 \%$ for an event with a probability of $0.1 \%$.

Absolute, relative and adjusted relative frequencies (i.e. omitting patients with missing data) were calculated. Multiple entries were possible for some items and were counted; therefore, the sum of relative frequencies could exceed $100 \%$. The number of patients giving multiple replies was recorded in each case. To assess the effects over time on the outcome variables, repeated measures analyses of variance were conducted post hoc using multivariate analysis of variance (MANOVA), and effect sizes $[28,37]$ were calculated using Cohen's $d$ [10] for dependent samples, by dividing the difference between the means of Visit 1 and Visit 3 with a variable including the pooled standard deviations (SD) for Visits 1 and 3, and the bivariate correlation ( $r$ ) between the two visits, as follows:

$d=$

$\frac{\mathrm{Mean}_{\text {visit1 }}-\mathrm{Mean}_{\text {visit3 }}}{\sqrt{\left(\mathrm{SD}_{\text {visit1 }}\right)^{2}+\left(\mathrm{SD}_{\text {visit3 }}\right)^{2}-2 \times r_{\text {visit }, \text { visit3 }} \times \mathrm{SD}_{\text {visit1 }} \times \mathrm{SD}_{\text {visit3 }}}}$

In order to calculate (post hoc) the normalisation rates for ADHD symptoms and functional impairment, a cut-off of 1 was defined on the ADHD total score and the functional impairment score obtained at Visit 3 on the
FBB-ADHD scale (both parent- and teacher-rated). The same cut-off was used in the Multimodal Treatment study of ADHD (MTA) study on similar rating scales assessing ADHD symptoms as defined by DSM-IV [41]; this cut-off was based on the ICD-10/DSM-IV criteria, which state that low severity of the specified behaviours (i.e. in the range from $0=$ not at all to $1=$ just a little on the FBB-ADHD scale) would not be sufficient to qualify them as symptoms of ADHD or ODD. In addition, norms for the FBB-ADHD parent-rated scores show that approximately $75-80 \%$ of school-age children manifest a total score of 1 or lower [13].

\section{Results}

In total, 852 patients were recruited to the study, of whom 822 were considered evaluable; 30 patients were excluded from the analysis because of invalid data. Of the 822 evaluable patients, 777 completed all three planned visits. The number of patients documented at each visit, and data on the termination of treatment are presented in Fig. 1. The most frequent reasons for early discontinuation were lack of effectiveness (47 patients, 5.72\%) and AEs (26 patients, $3.16 \%$ ). The mean duration of treatment was 2.26 months, ranging from 5 days to over 12 months; overall, the duration of treatment was greater than 138 patient-years.

\section{Patient characteristics}

Baseline patient demographics, ADHD diagnosis and the most frequent concomitant diseases are presented in Table 1. More boys than girls were included in the study, and the mean age was 10.04 years, with no difference between boys and girls; the most common age was 9 years (16.71\%). The majority of children (58.09\%) attended primary school, most frequently third grade (8- to 9-yearolds). Most patients had a disturbance of activity and attention (ICD code F90.0), which is similar to ADHD combined type according to DSM-IV, followed by hyperkinetic conduct disorder (F90.1) and other HKD (F90.8). Hyperkinetic conduct disorder was more frequent in boys, and other HKDs were less frequent in patients aged 11 and under $(5.94 \%$ versus $12.08 \%)$, particularly in boys. The time when ADHD was most impairing (counting multiple responses) was the school morning $(81.10 \%)$, followed by early afternoon $(69.34 \%)$, late afternoon $(51.06 \%)$, early morning (43.55\%) and evening (33.29\%), according to physician ratings based on parent information.

A total of $574(69.83 \%)$ children had been treated previously with other MPH formulations, such as MPH-IR (most often Medikinet ${ }^{\circledR}$, Medice, Germany) once or several times daily or MPH-MR (most often Medikinet $^{\circledR}$ XL, 
Fig. 1 Patient flow through the study (intent-to-treat population)

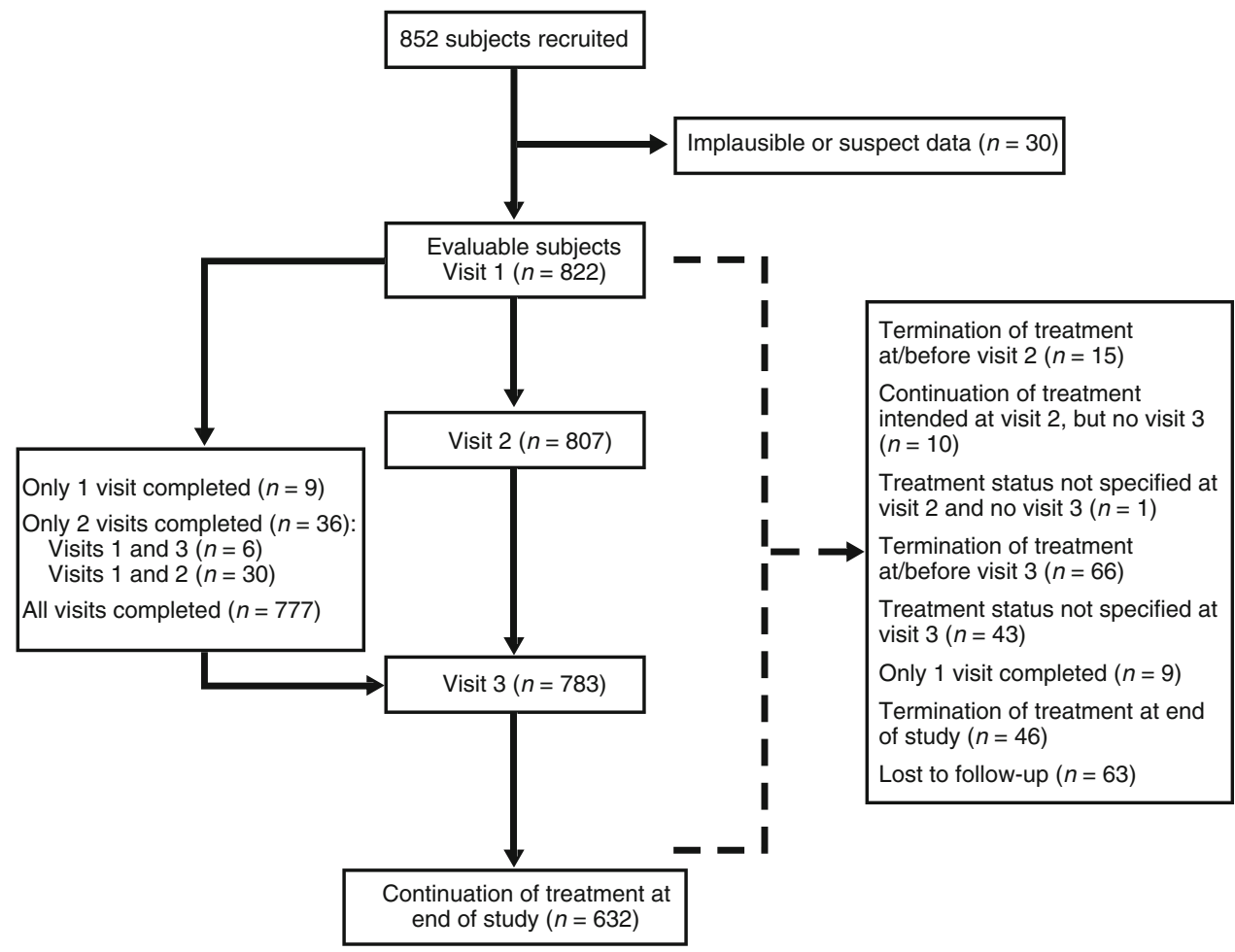

\begin{tabular}{llll}
\hline & Total & Male & Female \\
\hline Baseline demographics $(N=822)$ & & & \\
Patients, $n(\%)^{\mathrm{a}}$ & $816(100)$ & $663(81.25)$ & $153(18.75)$ \\
Age, years $(\text { mean }[\mathrm{SD}])^{\mathrm{b}}$ & $10.04(2.47)$ & $10.06(2.47)$ & $9.94(2.49)$ \\
Height, cm (mean [SD] $)^{\mathrm{c}}$ & $143.75(15.10)$ & $144.01(15.37)$ & $142.54(13.90)$ \\
Weight, kg (mean [SD] $)^{\mathrm{d}}$ & $37.98(13.60)$ & $38.18(13.41)$ & $37.08(14.46)$ \\
BMI, kg/m ${ }^{2}(\text { mean }[\mathrm{SD}])^{\mathrm{e}}$ & $17.91(3.41)$ & $17.92(3.27)$ & $17.83(3.97)$ \\
ADHD diagnosis, $n(\%)$ & $N=776^{\mathrm{f}}$ & $N=634$ & $N=142$ \\
F90.0: disturbance of activity/attention & $430(55.41)$ & $345(54.42)$ & $85(59.86)$ \\
F90.1: hyperkinetic conduct disorder & $282(36.34)$ & $246(38.80)$ & $36(25.35)$ \\
F90.8: other hyperkinetic disorders & $64(8.25)$ & $43(6.78)$ & $21(14.79)$ \\
\hline
\end{tabular}

Table 1 Baseline demographics and disease characteristics
$A D H D$ attention deficit hyperactivity disorder, $B M I$ body mass index, $S D$ standard deviation; ${ }^{\text {a }} N=816$ patients;

${ }^{\mathrm{b}} N=808 ;{ }^{\mathrm{c}} N=764$;

${ }^{\mathrm{d}} N=786 ;{ }^{\mathrm{e}} N=758 ;$

${ }^{\mathrm{f}}$ ADHD diagnosis is not specified for 46 patients third dose $(20.09 \%)$, side-effects $(8.95 \%)$, too late an onset of effect $(5.02 \%)$ or other reasons $(12.09 \%)$.

ADHD-CGI-S scores for core symptoms at baseline indicated that $17.17 \%$ of patients entering the study had mild symptoms, $59.14 \%$ had moderate symptoms, and $22.44 \%$ had severe symptoms. ADHD-associated problems were rated mild in $32.55 \%$ of patients, moderate in $48.08 \%$ and severe in $12.23 \%$. Inattention was the most severe of the core symptoms, with a mean (SD) score of $2.1(0.75)$, and learning difficulties were the most severe associated symptom, with a mean (SD) score of 1.83 (0.93).

The SDQ-P questionnaire (completed by parents) showed that $67.13 \%$ of patients had an overall difficulty score of abnormal, in contrast with the reference population $(27.63 \%)$, problems remembering to take the second or 
expected value of $10 \%$ [38]. The difference from the reference population was apparent in all SDQ subscales: emotional symptoms (35.73\% abnormal, $15.79 \%$ borderline and $48.48 \%$ normal), conduct problems $(42.30 \%$ abnormal, $15.67 \%$ borderline and $42.02 \%$ normal), hyperactivity $(57.20 \%$ abnormal, $14.54 \%$ borderline and $28.25 \%$ normal) and peer relationship problems $(35.60 \%$ abnormal, $14.13 \%$ borderline and $50.28 \%$ normal). The difference was less pronounced only in pro-social behaviour $(14.27 \%$ abnormal, $14.40 \%$ borderline and $71.33 \%$ normal).

\section{Administration of Equasym XL ${ }^{\circledR}$}

Dosing data are presented in Fig. 2. The daily dose of Equasym $\mathrm{XL}^{\circledR}$ administered during the study ranged from $10 \mathrm{mg}$ to $120 \mathrm{mg}$; the maximum recommended daily dose $(60 \mathrm{mg} / \mathrm{day})$ was exceeded in six patients. As expected, the daily MPH dosage during previous treatment was substantially lower for patients receiving MPH-IR once daily compared with those receiving of MPH-IR administered several times per day or MPH-MR.

On average, at Visit 1, the physician prescribed Equasym $\mathrm{XL}^{\circledR}$ at a higher dosage than prior medication in the group previously treated with once-daily MPH-IR, at a similar dosage in the group previously treated with repeated MPH-IR, and at a lower dosage in the group previously treated with an alternative MPH-MR formulation. In the subgroup with no previous medication, the mean prescribed dosage of Equasym $\mathrm{XL}^{\circledR}$ was lower than all the other subgroups. Dosages slightly increased from Visit 1 to Visit 3, indicating that the physician prescribed Equasym $\mathrm{XL}^{\circledR}$ according to recommended clinical practice, i.e. starting with a lower dose and subsequently titrating up according to the needs of the patient.

\section{Effectiveness}

Statistical analyses of effectiveness outcomes are summarised in Table 2. For all outcome measures, a statistically significant decrease was found in ADHD symptoms, ODD symptoms and associated functional impairment, as well as an increase in attention-reflexivity as rated by parents, teachers and clinicians. These results remain statistically significant after Bonferroni correction for multiple testing, and effect sizes vary from a small effect (Cohen's $d=0.30$ ) to a large effect (Cohen's $d=1.17$ ); the largest change was observed for CGI-S (Cohen's $d=1.17$ ).

According to CGI-I ratings, ADHD core symptoms improved during treatment with Equasym $\mathrm{XL}^{\circledR}$ in 524/692 $(75.73 \%)$ patients, stayed unchanged in $123(17.77 \%)$ and worsened in $45(6.50 \%)$ (Fig. 3a). Similarly, ADHDassociated problems improved in 451/676 (66.71\%) children, remained unchanged in $182(26.92 \%)$ and worsened in $43(6.37 \%)$ (Fig. 3b).

The severity profile of core symptoms and associated problems at Visit 1 and at the last visit after Visit 1 (either Visit 2 or Visit 3), according to CGI-S ratings, is shown in Fig. 4: Improvement was observed in all symptoms and problems, with a particularly strong reduction in core symptoms and learning difficulties.

At the final examination after 6-12 weeks of treatment (Visit 3), physicians were asked to provide a global evaluation of the effectiveness of Equasym $\mathrm{XL}^{\circledR}$ according to their medical judgement. This was collected for 721 children, and effectiveness was rated as very good in 255 patients (35.37\%), good in $312(43.27 \%)$, moderate in 108 $(14.98 \%)$ and poor in $46(6.38 \%)$.

Large reductions in ADHD symptoms were also found for parent-rated ADHD symptoms according to ICD-10/ DSM-IV (Table 2, FBB-ADHD, ADHD total: Cohen's
Fig. 2 Previous treatment dose by body weight at baseline and Equasym XL ${ }^{\circledR}$ dose by body weight prescribed at Visit 1 , Visit 2 and Visit 3, by prior treatment subgroup. MPH-MR, modified-release methylphenidate; MPH-IR, immediate-release methylphenidate; $S E$ standard error

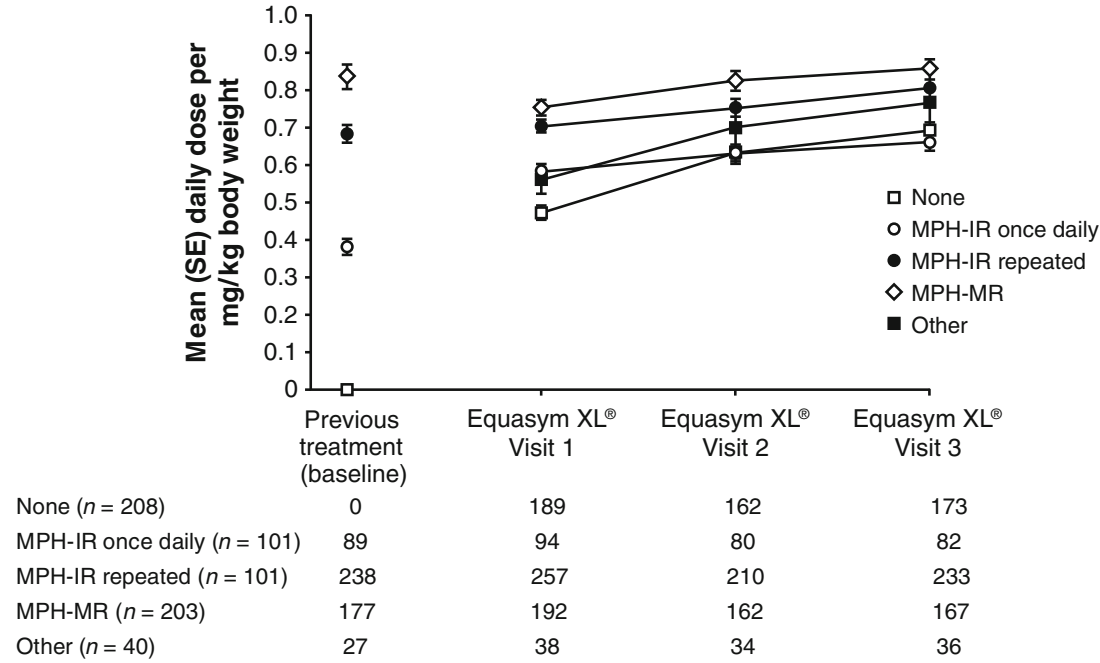


Table 2 Statistical analysis summary of CGI-S, parent and teacher FBB-ADHD and DAYAS scores

\begin{tabular}{|c|c|c|c|c|c|c|c|c|c|}
\hline \multirow[t]{3}{*}{ Scales } & \multirow[t]{3}{*}{$N$} & \multicolumn{6}{|c|}{ Assessment point } & \multicolumn{2}{|c|}{ Main effect MANOVA and effect size } \\
\hline & & \multicolumn{2}{|l|}{ Visit 1} & \multicolumn{2}{|c|}{ Visit 2} & \multicolumn{2}{|c|}{ Visit 3} & \multirow[t]{2}{*}{$\mathrm{F}^{*}$} & \multirow{2}{*}{$\begin{array}{l}\text { Cohen's } d \\
\text { (Visit 1-Visit 3) }\end{array}$} \\
\hline & & Mean & SD & Mean & SD & Mean & SD & & \\
\hline \multicolumn{10}{|l|}{ Clinical rating } \\
\hline Global impression (CGI-S) & 634 & 2.02 & 0.67 & 1.43 & 0.69 & 1.07 & 0.65 & 447.5 & 1.17 \\
\hline \multicolumn{10}{|l|}{ Parent ratings (FBB-ADHD) } \\
\hline Inattention & 701 & 1.87 & 0.63 & 1.35 & 0.60 & 1.21 & 0.58 & 334.5 & 0.95 \\
\hline Hyperactivity/impulsivity & 699 & 1.43 & 0.79 & 1.02 & 0.70 & 0.86 & 0.65 & 256.4 & 0.85 \\
\hline ADHD total & 699 & 1.63 & 0.62 & 1.17 & 0.59 & 1.02 & 0.56 & 356.2 & 1.00 \\
\hline Functional impairment & 698 & 1.83 & 0.73 & 1.38 & 0.73 & 1.15 & 0.71 & 238.2 & 0.82 \\
\hline Attention-reflexivity & 699 & 0.88 & 0.62 & 1.14 & 0.64 & 1.22 & 0.65 & 87.8 & 0.49 \\
\hline \multicolumn{10}{|l|}{ Teacher ratings (FBB-ADHD) } \\
\hline Inattention & 522 & 1.60 & 0.73 & 1.27 & 0.67 & 1.11 & 0.66 & 123.5 & 0.69 \\
\hline Hyperactivity/impulsivity & 521 & 1.07 & 0.85 & 0.81 & 0.73 & 0.68 & 0.66 & 73.3 & 0.53 \\
\hline ADHD total & 520 & 1.31 & 0.71 & 1.02 & 0.63 & 0.88 & 0.59 & 110.9 & 0.65 \\
\hline Functional impairment & 519 & 1.50 & 0.89 & 1.17 & 0.80 & 0.98 & 0.76 & 98.8 & 0.62 \\
\hline Attention-reflexivity & 511 & 0.98 & 0.63 & 1.16 & 0.64 & 1.24 & 0.63 & 44.5 & 0.41 \\
\hline \multicolumn{10}{|l|}{ Day profile-parent (DAYAS-P) } \\
\hline \multicolumn{10}{|l|}{ Total score } \\
\hline Morning before school & 682 & 1.37 & 0.77 & 1.08 & 0.73 & 1.02 & 0.72 & 96.1 & 0.51 \\
\hline Afternoon & 668 & 1.51 & 0.68 & 1.09 & 0.63 & 0.94 & 0.61 & 209.4 & 0.78 \\
\hline Late afternoon & 685 & 1.61 & 0.68 & 1.30 & 0.64 & 1.20 & 0.64 & 125.1 & 0.59 \\
\hline Evening & 683 & 1.48 & 0.74 & 1.29 & 0.72 & 1.20 & 0.72 & 56.4 & 0.40 \\
\hline \multicolumn{10}{|l|}{ ADHD symptoms } \\
\hline Morning before school & 681 & 1.38 & 0.81 & 1.09 & 0.78 & 1.02 & 0.78 & 80.3 & 0.47 \\
\hline Afternoon & 667 & 1.55 & 0.71 & 1.11 & 0.66 & 0.94 & 0.64 & 217.0 & 0.77 \\
\hline Late afternoon & 682 & 1.65 & 0.70 & 1.35 & 0.65 & 1.25 & 0.67 & 103.3 & 0.54 \\
\hline Evening & 679 & 1.50 & 0.77 & 1.32 & 0.76 & 1.23 & 0.76 & 41.7 & 0.35 \\
\hline \multicolumn{10}{|l|}{ ODD symptoms } \\
\hline Morning before school & 678 & 1.28 & 0.88 & 1.01 & 0.79 & 0.95 & 0.79 & 59.8 & 0.40 \\
\hline Afternoon & 660 & 1.35 & 0.82 & 1.01 & 0.73 & 0.89 & 0.71 & 102.5 & 0.55 \\
\hline Late afternoon & 679 & 1.49 & 0.83 & 1.20 & 0.77 & 1.11 & 0.76 & 84.3 & 0.48 \\
\hline Evening & 674 & 1.41 & 0.87 & 1.20 & 0.83 & 1.13 & 0.79 & 45.5 & 0.36 \\
\hline \multicolumn{10}{|c|}{ Day profile-teacher (DAYAS-T) } \\
\hline \multicolumn{10}{|l|}{ Total score } \\
\hline Morning first half & 515 & 1.07 & 0.74 & 0.84 & 0.64 & 0.73 & 0.60 & 57.3 & 0.47 \\
\hline Morning second half & 494 & 1.42 & 0.81 & 1.10 & 0.72 & 0.96 & 0.69 & 95.3 & 0.61 \\
\hline \multicolumn{10}{|l|}{ ADHD symptoms } \\
\hline Morning first half & 515 & 1.16 & 0.78 & 0.91 & 0.67 & 0.78 & 0.63 & 63.2 & 0.50 \\
\hline Morning second half & 494 & 1.60 & 0.85 & 1.21 & 0.76 & 1.06 & 0.72 & 111.6 & 0.66 \\
\hline \multicolumn{10}{|l|}{ ODD symptoms } \\
\hline Morning first half & 514 & 0.83 & 0.81 & 0.67 & 0.69 & 0.60 & 0.66 & 24.4 & 0.30 \\
\hline Morning second half & 492 & 1.09 & 0.91 & 0.87 & 0.81 & 0.74 & 0.76 & 42.6 & 0.41 \\
\hline
\end{tabular}

$\overline{A D H D}$ attention deficit hyperactivity disorder, $C G I-S$ clinical global impression severity, DAYAS day profile of ADHD assessment, DAYAS-P/T DAYAS-parent/teacher, $F B B-A D H D$ Fremdbeurteilungsbogen für Aufmerksamkeitsdefizit-Hyperaktivitätsstörung, $M$ mean, MANOVA multivariate analysis of variance, $O D D$ oppositional defiant disorder, $S D$ standard deviation

* All effects are statistically significant at $P<0.001$ 
Fig. 3 CGI-I scores. a Rating of change of ADHD core symptoms between Visit 1 and Visit 3 ( $n=692)$. b Rating of change of ADHD-associated problems between Visit 1 and Visit $3(n=676)$. ADHD, attention deficit hyperactivity disorder; CGI-I, clinical global impression improvement
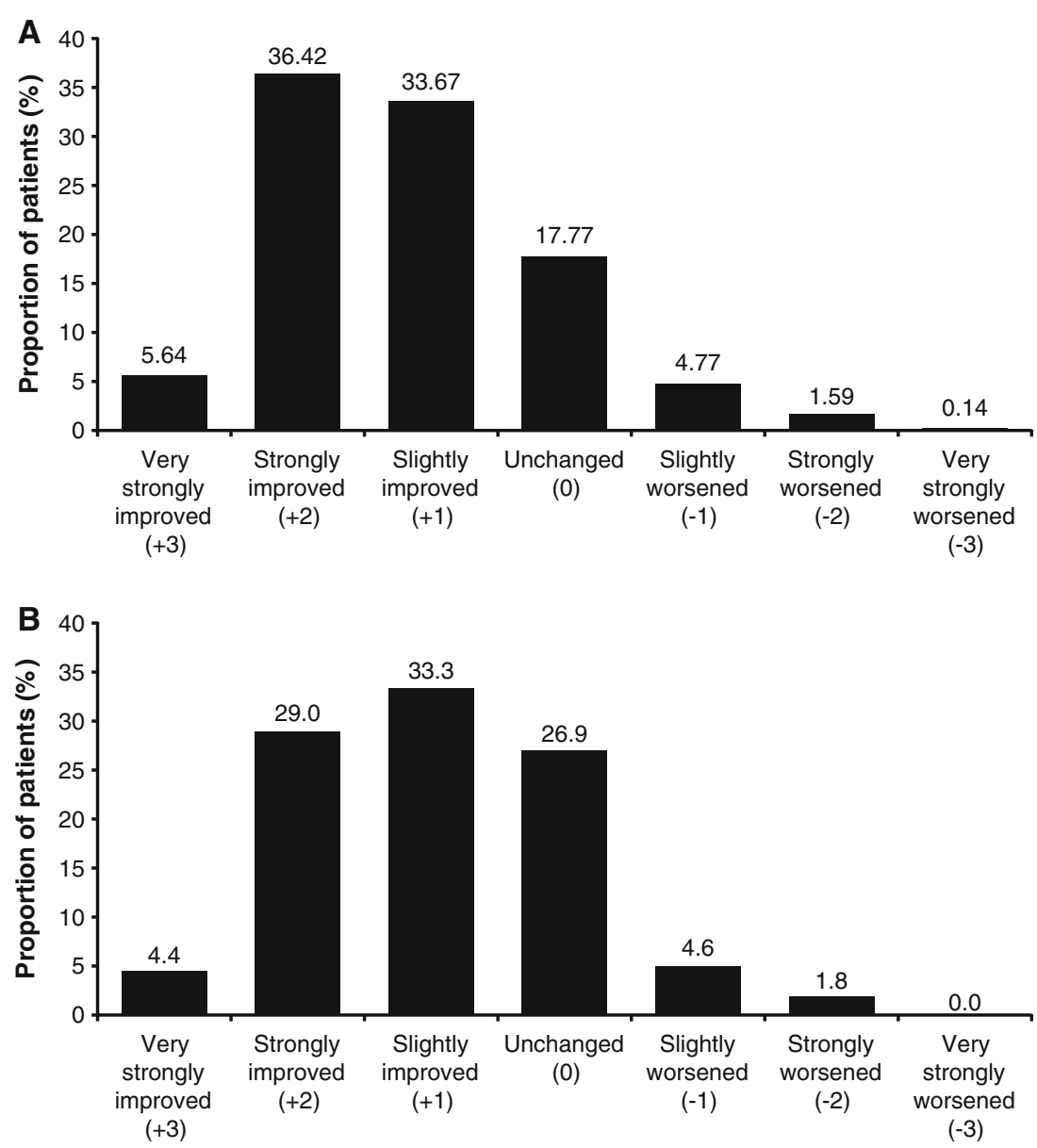

Fig. 4 CGI-S profile of ADHD core symptoms and associated problems at Visit 1 and at last visit. ADHD, attention deficit hyperactivity disorder; CGI-S, clinical global impression severity. Mean values: $0=$ not at all; $1=$ just a little;

$2=$ pretty much; $3=$ very much

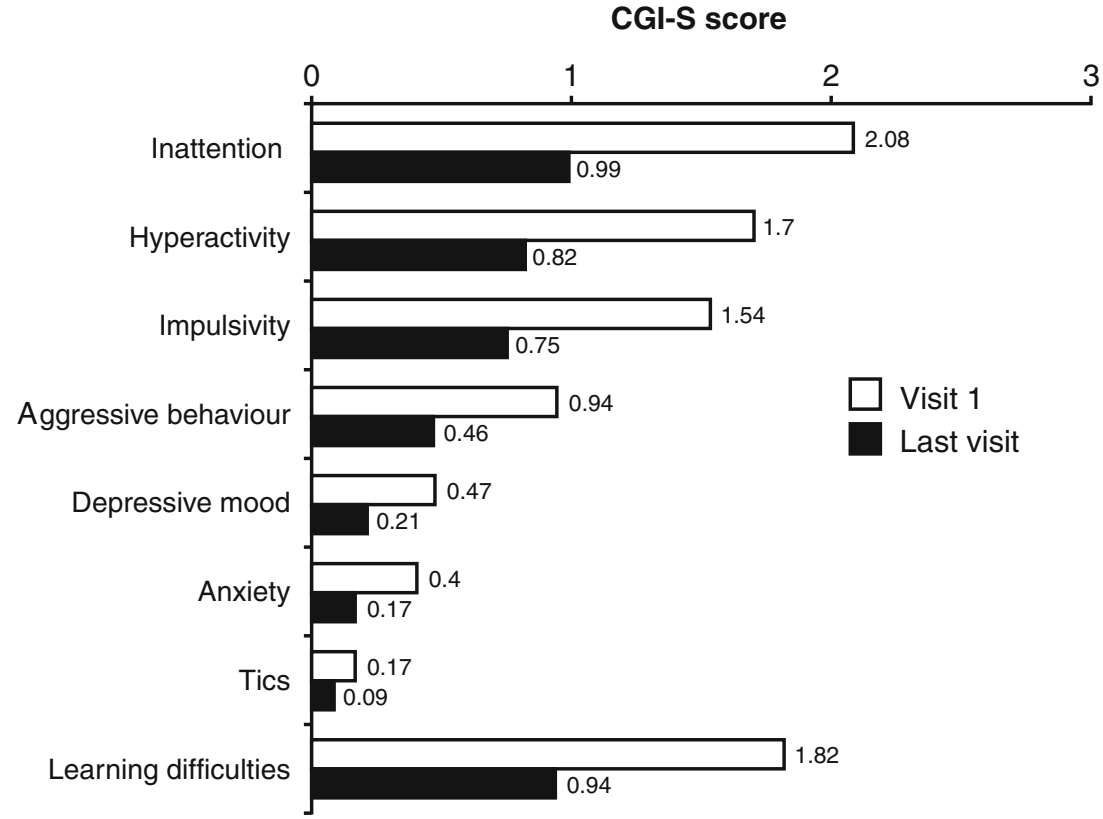

$d=1.00$ ), while the symptom reduction based on teacher ratings was in the moderate range (Table 2, FBB-ADHD, ADHD total: Cohen's $d=0.65$ ). Figure 5 shows the scores on the FBB-ADHD scales at Visit 1 and last visit as rated by parents and teachers. Similar effects were found for the subscales of hyperactivity/impulsivity and inattention, and 
Fig. 5 FBB-ADHD scores at

Visit 1 and at last visit, as assessed by teachers and

Fremdbeurteilungsbogen für AufmerksamkeitsdefizitHyperaktivitätsstörung. Mean values: $0=$ not at all; $1=$ just a little; $2=$ pretty much; $3=$ very much parents. FBB-ADHD,

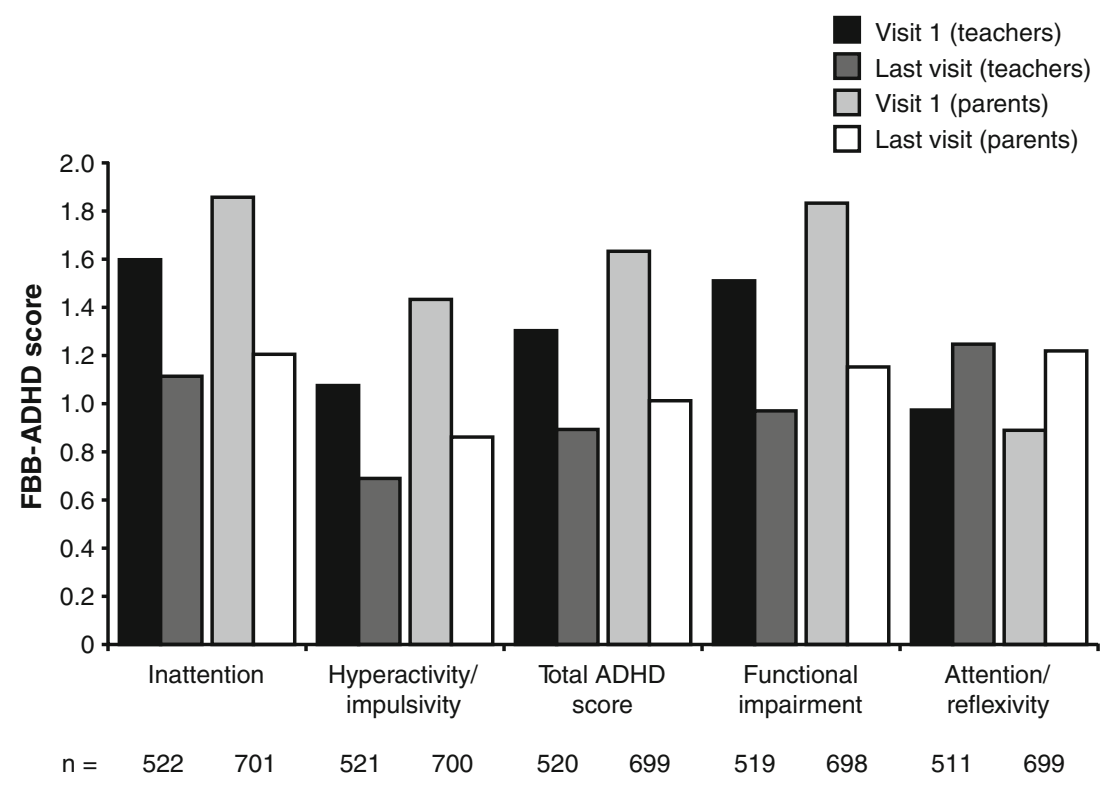

Table 3 Percentage of patients below a score of 1 in the ADHD total and functional impairment ratings at Visit 1, Visit 2 and Visit 3 (FBB-ADHD)

\section{$A D H D$ attention deficit} hyperactivity disorder, $F B B$ $A D H D$ Fremdbeurteilungsbogen für AufmerksamkeitsdefizitHyperaktivitätsstörung

\begin{tabular}{|c|c|c|c|c|c|c|c|}
\hline \multirow[t]{2}{*}{ Rating } & \multirow[t]{2}{*}{$N$ (total) } & \multicolumn{2}{|c|}{ Visit 1} & \multicolumn{2}{|c|}{ Visit 2} & \multicolumn{2}{|c|}{ Visit 3} \\
\hline & & $n$ & $\%$ & $n$ & $\%$ & $n$ & $\%$ \\
\hline \multicolumn{8}{|l|}{ Parents } \\
\hline ADHD total & 699 & 114 & 16.31 & 302 & 43.20 & 379 & 54.22 \\
\hline Functional impairment & 698 & 76 & 10.89 & 185 & 26.50 & 251 & 35.96 \\
\hline \multicolumn{8}{|l|}{ Teachers } \\
\hline ADHD total & 520 & 191 & 36.73 & 277 & 53.26 & 336 & 64.62 \\
\hline Functional impairment & 519 & 135 & 26.01 & 196 & 37.76 & 238 & 45.86 \\
\hline
\end{tabular}

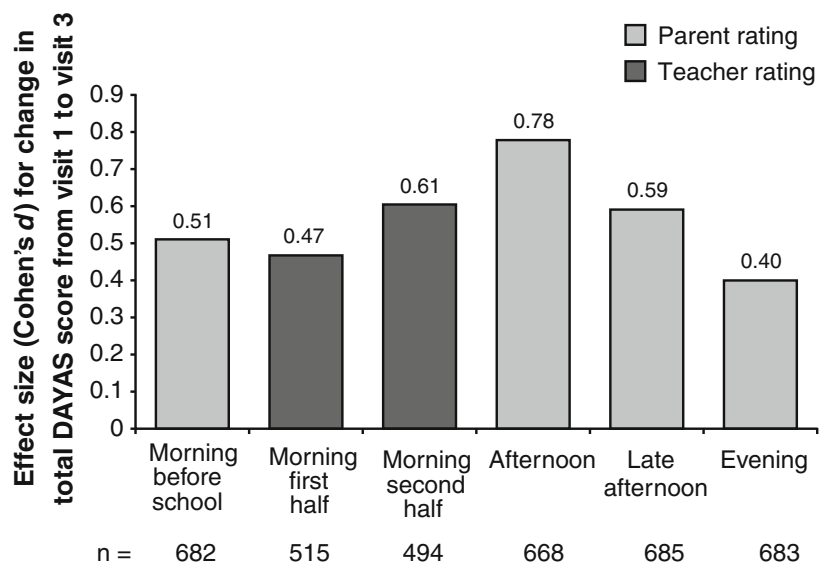

Fig. 6 Effect sizes (Cohen's $d$ ) for the reduction in total DAYAS scores between Visit 1 and Visit 3 throughout the day. DAYAS, day profile of attention deficit hyperactivity disorder assessment

symptom changes were observed in the second half of the school morning (rated by teachers) and in the early afternoon (rated by parents), while changes in the first half of the school morning (teachers) and in the late afternoon of effect sizes as calculated in Table 2. The strongest 
(parents) were somewhat lower. The smallest changes were observed in the early morning and in the evening at home (both rated by parents).

\section{Safety}

Overall, 313 AEs were recorded in 209/822 patients (25.43\%). For 93 AEs (mainly tics) in 88 patients, the physician failed to specify whether the AE occurred under previous treatment or current treatment; these events are included here to provide a conservative analysis. One patient had six AEs, three patients had five AEs, four patients had four AEs, 16 patients had three AEs, 43 patients had two AEs, and 142 patients had only one AE. The most frequent AEs, by MedDRA 11.1 preferred code, were psychiatric disorders (19.83\% of all patients), metabolism and nutrition disorders $(2.43 \%)$ and gastrointestinal disorders $(2.19 \%)$. A list of AEs showing a frequency higher than $0.30 \%$ is presented in Table 4. Most AEs were mild or moderate in intensity, although 47 events in 29 patients were considered severe. Severity was unrecorded for 148 AEs (120 patients).

In total, 38 AEs in 21 patients were classified as serious (2.55\%); no serious AE resulted in death. In 26 (3.16\%) cases, treatment was discontinued as a result of AEs. At the end of the study, 104 events in 66 patients $(8.03 \%)$ had resolved, 31 events in 25 patients $(3.04 \%)$ were unresolved, and 25 events in 17 patients $(2.07 \%)$ had not changed since onset; the clinical outcome of 14 AEs in 11 patients $(1.34 \%)$ was unknown to the physician, and for 139 AEs in 116 patients $(14.11 \%)$, there was no information about the outcome. No action was required for 83 AEs in 64 patients

Table 4 AEs, by MedDRA 11.1 preferred code $(n=822)$

\begin{tabular}{|c|c|c|c|}
\hline $\begin{array}{l}\text { Adverse event } \\
\text { (MedDRA 11.1) }\end{array}$ & $\begin{array}{l}\text { Number of } \\
\text { AEs }\end{array}$ & $\begin{array}{l}\text { Number of } \\
\text { cases }\end{array}$ & $\begin{array}{l}\text { Frequency } \\
(\%)\end{array}$ \\
\hline Tic & 106 & 100 & 12.17 \\
\hline Aggression & 32 & 31 & 3.77 \\
\hline Depressed mood & 13 & 13 & 1.58 \\
\hline Initial insomnia & 11 & 11 & 1.34 \\
\hline Headache & 10 & 9 & 1.09 \\
\hline Anorexia & 9 & 9 & 1.09 \\
\hline Gastrointestinal pain & 9 & 9 & 1.09 \\
\hline Nausea & 9 & 9 & 1.09 \\
\hline Sleep disorder & 9 & 9 & 1.09 \\
\hline Decreased appetite & 9 & 8 & 0.97 \\
\hline Not evaluable & 7 & 6 & 0.73 \\
\hline Depression & 4 & 4 & 0.49 \\
\hline Onychophagia & 3 & 3 & 0.36 \\
\hline Tremor & 3 & 3 & 0.36 \\
\hline
\end{tabular}

$A E$ adverse event, MedDRA Medical Dictionary of Regulatory Activities
(7.79\%), symptomatic therapy was prescribed for 30 AEs in 20 patients $(2.43 \%)$, and the Equasym $\mathrm{XL}^{\circledR}$ dose was reduced as a consequence of 13 AEs in 11 patients $(1.34 \%) ; 6$ AEs in 4 patients $(0.49 \%)$ led to a temporary interruption of treatment, and 40 AEs in 26 patients (3.16\%) led to treatment discontinuation. A total of 27 AEs in 18 patients $(2.19 \%)$ were considered related to the study treatment, 48 AEs in 34 patients $(4.14 \%)$ were considered likely to be treatment related, 70 AEs in 47 patients $(5.72 \%)$ were considered possibly treatment related, and 25 AEs in 22 patients $(2.68 \%$ ) were considered unlikely to be related to treatment.

Physicians assessed the global tolerability of Equasym $\mathrm{XL}^{\circledR}$ at the final examination at Visit 3. Tolerability was considered to be very good in $415 / 734$ patients $(56.54 \%)$, good in $270 / 734(36.78 \%)$ patients, moderate in $33 / 734$ $(4.50 \%)$ patients and poor in $16 / 734(2.18 \%)$ patients. No global assessment was provided for 88 patients.

\section{Discussion}

This large observational study used multiple outcomes and different raters to assess ADHD profile across the day in a natural setting and, to our knowledge, is the first such study. Results showed that Equasym XL ${ }^{\circledR}$ was well tolerated and effective for the treatment of children and adolescents with ADHD in daily clinical practice conditions.

The efficacy and safety of this MPH-MR formulation had previously been assessed in three placebo-controlled clinical trials [19, 23, 42] and in one 3-week post-marketing study [12]. The population analysed in this study is similar in terms of demographics, ADHD diagnosis and severity of ADHD symptoms at baseline to those analysed in previous trials. However, the observational period of this post-marketing study is longer; the final examination was in fact carried out after 6-12 weeks of treatment, compared with 1-3 weeks in clinical trials. Also, the nature of this study is different to a clinical trial as it is an observation of real-life treatment providing a comprehensive assessment with ratings from physicians, parents and teachers. Compared with other observational trials of MPH-MR formulations [12, 18, 24, 26, 35], the OBSEER study is the largest, and one of the most rigorous, to date.

Three-quarters $(75.73 \%)$ of patients showed improvements in ADHD core symptoms on the CGI-I scale during treatment with Equasym $\mathrm{XL}^{\circledR}$ compared with the prior treatment status (either receiving medication or not), and only $6.50 \%$ of patients had worsened scores. The rate of improvement was similar to that observed in the previous open-label Equasym XL ${ }^{\circledR}$ trial $(65 \%$ of patients had ratings of very much or much improved) [12], although the criteria for efficacy were different. This is similar to results from a 
6-month open-label study of the MPH transdermal system in adolescents, where $75.9 \%$ of patients were classed as 'very much improved' or 'much improved' on the CGI-I scale [18]. In a 4-week, open-label study of Concerta in children (aged 6-13 years), CGI-I scores for ADHD symptoms were rated as improved for approximately $92 \%$ of patients [26].

Results from FBB-ADHD ratings confirm the CGI-I/S findings. For the improvement in symptoms according to total FBB-ADHD scores from Visits 1 to 3 , an effect size (Cohen's $d$ ) of 1.00 was calculated for parent ratings and 0.65 for teacher ratings. As nearly $70 \%$ of patients were already on medication at Visit 1 , these effect sizes might be considered larger than expected. In one meta-analysis of randomised controlled trials, effect sizes (standardised mean difference) of between 0.6 and 1.0 were calculated for the effects of MPH-MR treatment versus placebo [4]. Another meta-analysis of randomised controlled studies of short-acting MPH reported a standardised change score from pre- to post-assessment (mean weighted Cohen's $d$ ) of 1.53 (95\% confidence intervals [CI]: 1.23-1.82) for parent ratings of ADHD symptoms and 1.83 (95\% CI: 1.43-2.12) for teacher ratings [43].

Furthermore, the percentage of patients in the OBSEER study in the normal range for ADHD total and functional impairment scores on the FBB-ADHD, as rated by parents and teachers, increased from Visit 1 to Visit 3, with 54-65 and $36-46 \%$ of patients in the normal range for symptoms and overall impairment, respectively. By comparison, in the randomised MTA study, the percentage of patients in the normal range after 14 months of treatment was $56 \%$ for the group receiving MPH-IR (medication management group), according to combined ratings of ADHD and ODD symptoms from parents and teachers [41]. Thus, although cross-study comparisons must be treated with caution, particularly for studies with such different designs, results from this observational trial are comparable with those from randomised studies.

Similarly, ADHD-associated problems improved in twothirds $(66.71 \%)$ of patients and worsened in only $6.37 \%$. In teacher and parent assessments, behaviour improved compared with baseline at all six measured time points across the day, in particular in the second half of the school morning and in the early afternoon. These peak effectiveness times coincided with the times of day patients reported as being most problematic at the beginning of the study and covered homework time. Moreover, this day profile in a real-life situation is consistent with the mean plasma concentration of Equasym XL ${ }^{\circledR}$, which shows a peak $6 \mathrm{~h}$ after ingestion [20]; it is also in line with the pharmacodynamic profile across the day in a laboratory classroom situation described in the COMACS study [42], in which maximum effects were observed $1.5-6 \mathrm{~h}$ after administration.
AEs were recorded in one-quarter of patients, and the number and type of AEs were generally similar to prior Equasym XL ${ }^{\circledR}$ clinical trials $[12,19,23]$. However, comparison with other studies should be made with caution because the OBSEER study had a longer period of observation compared with clinical trials. Although the frequency of tics was over $12 \%$ in this study, it was similar to the frequency (13\% [teacher scores] and 7\% [parent scores]) reported for the Equasym XL ${ }^{\circledR}$ arm of a previous randomised controlled 3-week trial that excluded patients with a history of tics [23]. While early studies considered tics to be a contraindication to the use of stimulants for hyperactive syndromes [27], more recent evidence suggests that while stimulants may worsen pre-existing tics [30, 34], there is no support for an increased risk of first-onset tics $[22,36]$. As OBSEER was an observational study, patients with pre-existing tics were not excluded, neither were preexisting and emergent tics differentiated, so conclusions regarding this issue are limited. The number of serious AEs was notably higher in this study; 38 serious AEs were in fact observed in 21 patients out of 822 (2.5\%), compared with one serious $\mathrm{AE}$ in one patient out of $310(0.3 \%)$ treated with Equasym $\mathrm{XL}^{\circledR}$ in another observational study [12], one serious AE in one patient out of 139 (0.7\%) [19] or no serious AEs out of 155 patients [23] in the previous clinical trials. As noted earlier, this is possibly due to the longer period of observation and to the fact that for many AEs, it could not be excluded that they had already occurred under the previous medication. In addition, there was no global assessment of tolerability by physicians for $10.7 \%$ of patients, and being an observational study, there was little or no formal training of investigators for the assessment of seriousness of AEs, which might account for the difference in the number of serious AEs compared with previous trials.

There were several other limitations to this study. First, this was an open-label study without a control group; therefore, physicians and parents were not blinded to the study treatment or dose. Teachers were not formally informed of the change of treatment, and although they could have been told by parents or children, most were not aware. The lower effect sizes in teacher ratings may therefore be a more realistic picture of the real effects of Equasym $\mathrm{XL}^{\circledR}$, without the expectation effects that may have influenced the ratings by parents and the physician, who were not satisfied with the prior medication or the untreated status. Secondly, due to the design of the study, the results for the previously treated group can only be generalised to a population in which a switch to Equasym $\mathrm{XL}^{\circledR}$ is planned due to suboptimal effects of the prior medication. Distinct advantages of this study are the long period of observation and the use of multiple outcome measures with multiple informants. As it was an 
observational study, and no strict exclusion criteria were applied, this analysis describes the real population treated in clinical practice [39].

In conclusion, this study confirmed the effectiveness of Equasym $\mathrm{XL}^{\circledR}$ under the conditions of daily practice in which treatment with Equasym $\mathrm{XL}^{\circledR}$ was planned, as the response to treatment was positive for the majority of patients; the improvements observed are particularly striking because most children had already been treated with different formulations of the same active substance. The frequency and nature of AEs observed here are consistent with earlier studies. These results also suggest that Equasym $\mathrm{XL}^{\circledR}$ covers daily requirements effectively, in particular in the parts of the day when ADHD symptoms tend to be most impairing, possibly as a result of its 30:70 IR to MPH-MR content and/or its greater ease of administration.

Acknowledgments The authors would like to thank the following, for constructive review: Andreas Becker, $\mathrm{PhD}$ (University of Göttingen), Amina Elsner, MD, Simon Hatch, MD, Eugene Osei-Bonsu, MSc, Jonathan Smith, MSc, Monica Shaw, MD, and Alisa Woods, $\mathrm{PhD}$ (all Shire Pharmaceuticals Ltd/Shire Development Inc./Shire AG at the time of review). We take full responsibility for the contents of the manuscript but thank Monica Guidi, PhD, and Joanna Wright, DPhil (Caudex Medical, Oxford, UK, supported by Shire Development Inc.) for their assistance in preparing the outline and initial draft of the manuscript, including drawing figures and tables, and collating the comments of authors and other named contributors. The OBSEER study was funded by UCB. Additional statistical analyses and the preparation of the manuscript were supported by Shire Development Inc.

Conflict of interest Aribert Rothenberger has acted as a consultant or on advisory boards and/or as a speaker for Lilly, Shire Pharmaceuticals Ltd, Medice, Novartis and UCB. He has received research support from Shire Pharmaceuticals Ltd, the German Research Society and Schwaabe, and travel and educational grants from Shire Pharmaceuticals Ltd. Dieter Breuer has been a consultant for Lilly, Shire Pharmaceuticals Ltd, UCB and Medice. Anja Görtz-Dorten has no conflict of interest. Manfred Döpfner has received research grants and/or acted as a consultant or on advisory boards for UCB, Lilly, Shire Pharmaceuticals Ltd, Medice and Vifor.

This article is part of a supplement sponsored by Shire Development Inc.

Open Access This article is distributed under the terms of the Creative Commons Attribution Noncommercial License which permits any noncommercial use, distribution, and reproduction in any medium, provided the original author(s) and source are credited.

\section{References}

1. Adler LA, Chua HC (2002) Management of ADHD in adults. J Clin Psychiatry 63(Suppl 12):29-35

2. American Psychiatric Association (2000) Attention-deficit and disruptive behavior disorders. Attention-deficit/hyperactivity disorder. Diagnostic and statistical manual of mental disorders. 4th edn. American Psychiatric Association, Arlington, pp 85-103
3. Anderson VR, Keating GM (2006) Methylphenidate controlleddelivery capsules (EquasymXL, Metadate $\mathrm{CD}$ ): a review of its use in the treatment of children and adolescents with attentiondeficit hyperactivity disorder. Paediatr Drugs 8:319-333

4. Banaschewski T, Coghill D, Santosh P, Zuddas A, Asherson P, Buitelaar J, Danckaerts M, Dopfner M, Faraone SV, Rothenberger A, Sergeant J, Steinhausen HC, Sonuga-Barke EJ, Taylor E (2006) Long-acting medications for the hyperkinetic disorders. A systematic review and European treatment guideline. Eur Child Adolesc Psychiatry 15:476-495

5. Barkley RA, Fischer M, Smallish L, Fletcher K (2003) Does the treatment of attention-deficit/hyperactivity disorder with stimulants contribute to drug use/abuse? A 13-year prospective study. Pediatrics 111:97-109

6. Biederman J, Faraone SV (2005) Attention-deficit hyperactivity disorder. Lancet 366:237-248

7. Breuer D, Görtz-Dorten A, Rothenberger A, Döpfner M (2011) Assessment of daily profiles of ADHD and ODD symptoms, and symptomatology related to ADHD medication, by parent and teacher ratings. Eur Child Adolesc Psychiatry. doi:10.1007/ s00787-011-0206-0

8. Breuer D, Wolff MT, Dopfner M (2009) The assessment of Attention Deficit Hyperactivity Disorder (ADHD) by teacher ratings - validity and reliability of the FBB-HKS. Z Kinder Jugendpsychiatr Psychother 37:431-440

9. Bruhl B, Dopfner M, Lehmkuhl G (2000) Der Fremdbeurteilungsbogen für hyperkinetische Störungen (FBB-HKS) Prävalenz hyperkinetischer Störrungen im Elternurteil und psychometrische Kriterien. Kindheit und Entwicklung 9. S.:116-126

10. Cohen J (1988) Statistical power analysis for the behavioural sciences. Lawrence Erlbaum Associates, Hillsdale

11. Cutting LE, Koth CW, Mahone EM, Denckla MB (2003) Evidence for unexpected weaknesses in learning in children with attention-deficit/hyperactivity disorder without reading disabilities. J Learn Disabil 36:259-269

12. Dirksen SJ, D’Imperio JM, Birdsall D, Hatch SJ (2002) A postmarketing clinical experience study of Metadate CD. Curr Med Res Opin 18:371-380

13. Döpfner M, Görtz-Dorten A, Lehmkuhl G (2008) DiagnostikSystem für psychische Störungen nach ICD-10 und DSM-IV für Kinder- und Jugendliche (DISYPS-II). Huber, Bern

14. Döpfner M, Lehmkuhl G (1998) Diagnostik-System für Psychische Störungen im Kindes- und Jugendalter nach ICD-10 und DSM-IV (DISYPS-KJ). Huber, Bern

15. DuPaul GJ, McGoey KE, Eckert TL, VanBrakle J (2001) Preschool children with attention-deficit/hyperactivity disorder: impairments in behavioral, social, and school functioning. J Am Acad Child Adolesc Psychiatry 40:508-515

16. Erhart M, Döpfner M, Ravens-Sieberer U (2008) Psychometric properties of two ADHD questionnaires: comparing the Conners' scale and the FBB-HKS in the general population of German children and adolescents-results of the BELLA study. Eur Child Adolesc Psychiatry 17(Suppl 1):106-115

17. Faraone SV, Biederman J, Mick E (2006) The age-dependent decline of attention deficit hyperactivity disorder: a meta-analysis of follow-up studies. Psychol Med 36:159-165

18. Findling RL, Katic A, Rubin R, Moon E, Civil R, Li Y (2010) A 6-month, open-label, extension study of the tolerability and effectiveness of the methylphenidate transdermal system in adolescents diagnosed with attention-deficit/hyperactivity disorder. J Child Adolesc Psychopharmacol 20:365-375

19. Findling RL, Quinn D, Hatch SJ, Cameron SJ, DeCory HH, McDowell M (2006) Comparison of the clinical efficacy of twicedaily Ritalin and once-daily Equasym XL with placebo in children with Attention Deficit/Hyperactivity Disorder. Eur Child Adolesc Psychiatry 15:450-459 
20. Gonzalez MA, Pentikis HS, Anderl N, Benedict MF, DeCory HH, Dirksen SJ, Hatch SJ (2002) Methylphenidate bioavailability from two extended-release formulations. Int J Clin Pharmacol Ther 40:175-184

21. Goodman R (1997) The Strengths and Difficulties Questionnaire: a research note. J Child Psychol Psychiatry 38:581-586

22. Graham J, Banaschewski T, Buitelaar J, Coghill D, Danckaerts M, Dittmann RW, Dopfner M, Hamilton R, Hollis C, Holtmann M, Hulpke-Wette M, Lecendreux M, Rosenthal E, Rothenberger A, Santosh P, Sergeant J, Simonoff E, Sonuga-Barke E, Wong IC, Zuddas A, Steinhausen HC, Taylor E (2010) European guidelines on managing adverse effects of medication for ADHD. Eur Child Adolesc Psychiatry 20:17-37

23. Greenhill LL, Findling RL, Swanson JM (2002) A double-blind, placebo-controlled study of modified-release methylphenidate in children with attention-deficit/hyperactivity disorder. Pediatrics 109:E39

24. Heger S, Trott GE, Meusers M, Schulz E, Rothenberger A, Rettig K, Medori R, Schreiner A, Remschmidt H (2006) Switching from a short-acting to a long-acting methylphenidate preparation: a multicentre, open study in children with ADHD. Z Kinder Jugendpsychiatr Psychother 34:257-265

25. Horrigan JP, Kohli RR (2002) The impact of dosing frequency on psychostimulant compliance in ADHD. NIMH-42nd Annual NCDEU Meeting Poster 56

26. Lee SI, Hong SD, Kim SY, Kim EJ, Kim JH, Kim JH, Park MK, Park S, Park JH, Oh EY, Lim TS, Cheong S, Cho IH, Choi JW (2007) Efficacy and tolerability of OROS methylphenidate in Korean children with attention-deficit/hyperactivity disorder. Prog Neuropsychopharmacol Biol Psychiatry 31:210-216

27. Lowe TL, Cohen DJ, Detlor J, Kremenitzer MW, Shaywitz BA (1982) Stimulant medications precipitate Tourette's syndrome. JAMA 247:1729-1731

28. Morris SB (2008) Estimating effect sizes from pretest-posttestcontrol group designs. Organ Res Methods 11:364-386

29. NIH (2000) National Institutes of Health consensus development conference statement: diagnosis and treatment of attention-deficit/hyperactivity disorder (ADHD). J Am Acad Child Adolesc Psychiatry 39:182-193

30. Palumbo D, Spencer T, Lynch J, Co-Chien H, Faraone SV (2004) Emergence of tics in children with ADHD: impact of once-daily OROS methylphenidate therapy. J Child Adolesc Psychopharmacol 14:185-194

31. Patrick KM (1987) Pharmacokinetics and actions of methylphenidate. In: Meltzer H (ed) Psychopharmacology, the third generation of progress. Raven Press, New York, pp 1387-1395

32. Pelham WE, Gnagy EM, Burrows-Maclean L, Williams A, Fabiano GA, Morrisey SM, Chronis AM, Forehand GL, Nguyen CA, Hoffman MT, Lock TM, Fielbelkorn K, Coles EK, Panahon CJ, Steiner RL, Meichenbaum DL, Onyango AN, Morse GD (2001) Once-a-day Concerta methylphenidate versus three-timesdaily methylphenidate in laboratory and natural settings. Pediatrics 107:E105

33. Polanczyk G, de Lima MS, Horta BL, Biederman J, Rohde LA (2007) The worldwide prevalence of ADHD: a systematic review and metaregression analysis. Am J Psychiatry 164:942-948
34. Poncin Y, Sukhodolsky DG, McGuire J, Scahill L (2007) Drug and non-drug treatments of children with ADHD and tic disorders. Eur Child Adolesc Psychiatry 16(Suppl 1):78-88

35. Remschmidt H, Hoare P, Ettrich C, Rothenberger A, Santosh P, Schmidt M, Spender Q, Tamhne R, Thompson M, Tinline C, Trott GE, Medori R (2005) Symptom control in children and adolescents with attention-deficit/hyperactivity disorder on switching from immediate-release MPH to OROS MPH Results of a 3-week open-label study. Eur Child Adolesc Psychiatry 14:297-304

36. Roessner V, Robatzek M, Knapp G, Banaschewski T, Rothenberger A (2006) First-onset tics in patients with attention-deficithyperactivity disorder: impact of stimulants. Dev Med Child Neurol 48:616-621

37. Rosnow RL, Rosenthal R (2009) Effect sizes: why, when and how to use them. J Psychol 217:6-14

38. Rothenberger A, Becker A, Erhart M, Wille N, Ravens-Sieberer U (2008) Psychometric properties of the parent strengths and difficulties questionnaire in the general population of German children and adolescents: results of the BELLA study. Eur Child Adolesc Psychiatry 17(Suppl 1):99-105

39. Rothenberger A, Becker A, Breuer D, Döpfner M (2011) An observational study of once-daily modified-release methylphenidate in ADHD: quality of life, satisfaction with treatment and adherence. Eur Child Adolesc Psychiatry. doi:10.1007/s00787011-0203-3

40. Shire Pharmaceuticals. Equasym XL SPC. 2011

41. Swanson JM, Kraemer HC, Hinshaw SP, Arnold LE, Conners CK, Abikoff HB, Clevenger W, Davies M, Elliott GR, Greenhill LL, Hechtman L, Hoza B, Jensen PS, March JS, Newcorn JH, Owens EB, Pelham WE, Schiller E, Severe JB, Simpson S, Vitiello B, Wells K, Wigal T, Wu M (2001) Clinical relevance of the primary findings of the MTA: success rates based on severity of ADHD and ODD symptoms at the end of treatment. J Am Acad Child Adolesc Psychiatry 40:168-179

42. Swanson JM, Wigal SB, Wigal T, Sonuga-Barke E, Greenhill LL, Biederman J, Kollins S, Nguyen AS, DeCory HH, Hirshe Dirksen SJ, Hatch SJ (2004) A comparison of once-daily extended-release methylphenidate formulations in children with attention-deficit/ hyperactivity disorder in the laboratory school (the Comacs Study). Pediatrics 113:e206-e216

43. Van der Oord S, Prins PJ, Oosterlaan J, Emmelkamp PM (2008) Efficacy of methylphenidate, psychosocial treatments and their combination in school-aged children with ADHD: a meta-analysis. Clin Psychol Rev 28:783-800

44. Wigal SB, Sanchez DY, DeCory HH, D'Imperio JM, Swanson JM (2003) Selection of the optimal dose ratio for a controlleddelivery formulation of methylphenidate. J Appl Res 3:46-63

45. Woerner W, Becker A, Friedrich C, Klasen H, Goodman R, Rothenberger A (2002) Normal values and evaluation of the German parents' version of Strengths and DIfficulties Questionnaire (SDQ): results of a representative field study. Z Kinder Jugendpsychiatr Psychother 30:105-112

46. World Health Organization. International Classification of Diseases (ICD-10) (1992) Geneva 